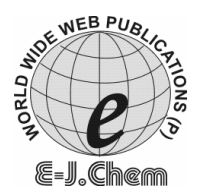

http://www.e-journals.net
ISSN: 0973-4945; CODEN ECJHAO

E-Journal of Chemistry

Vol. 5, No.3, pp. 529-538, July 2008

\title{
Synthesis, Characterization and Biological Activities of $\mathrm{Cu}$ (II), Co(II), Ni(II), Mn(II) and Fe(III) Complexes with Schiff Base Derived from 3-(4-Chloro- phenoxymethyl)-4-amino-5-mercapto-1,2,4-triazole
}

\author{
VIDYAVATI REDDY ${ }^{\S}$, NIRDOSH PATIL ${ }^{\#}$, \\ TUKARAM REDDY ${ }^{\S}$ and S. D. ANGADI ${ }^{\S *}$ \\ ${ }^{\S}$ Department of Studies and Research in Chemistry, \\ Gulbarga University, Gulbarga, 585106, Karnataka, India. \\ \#Appa Institute of Engineering and Technology, \\ Gulbarga, 585106, Karnataka, India. \\ angadi_sd2007@rediffmail.com
}

Received 8 December 2007; Accepted 28 January 2008

\begin{abstract}
Coordination complexes of $\mathrm{Cu}(\mathrm{II}), \mathrm{Co}(\mathrm{II}), \mathrm{Ni}(\mathrm{II}), \mathrm{Mn}(\mathrm{II})$ and Fe(III)with Schiff bases derived from 3-(4-chlorophenoxymethyl)-4-amino-5mercapto-1, 2, 4-triazole and substituted aldehydes have been synthesized. The complexes were characterized by elemental analysis, conductivity measurements, magnetic susceptibility data, electronic, IR, ESR and ${ }^{1} \mathrm{H}$ NMR spectral data. On the basis spectroscopic studies, the Schiff base is monobasic bidentate ligand having the composition $\mathrm{ML}_{2}\left(2 \mathrm{H}_{2} \mathrm{O}\right)$ Where $\mathrm{M}=\mathrm{Cu}(\mathrm{II}), \mathrm{Co}(\mathrm{II}), \mathrm{Ni}(\mathrm{II}), \mathrm{Mn}(\mathrm{II}), \mathrm{ML}_{2}\left(\mathrm{H}_{2} \mathrm{O}\right) \mathrm{Cl}$ Where $\mathrm{M}=\mathrm{Fe}(\mathrm{III})$. Various physicochemical data suggest a six coordinated octahedral geometry for $\mathrm{Cu}(\mathrm{II}), \mathrm{Co}(\mathrm{II}), \mathrm{Ni}(\mathrm{II}), \mathrm{Mn}$ (II) and $\mathrm{Fe}(\mathrm{III})$ complexes. The antibacterial activities of ligand and its complexes were screened by cup plate method.
\end{abstract}

Keywords: Triazoles, Metal complexes, Spectral, Magnetic susceptibility and Antimicrobial activity

\section{Introduction}

Schiff bases are important class of ligands in coordination chemistry and their complexing ability containing different donor atom is widely reported. The chemistry of transition metal complexes containing heterocyclic donor continues to be of interest on account of their biological importance. There is a growing interest in the studies on the metal complexes of Schiff bases derived from triazoles and its derivatives which are biologically important ligands ${ }^{1}$. Schiff base metal complexes have been widely studied because of their industrial 
and biological applications, several derivatives of these have been used as drugs. The triazole Schiff bases constitute one of the most important classes of $\mathrm{O}, \mathrm{N}$, and $\mathrm{S}$ donor atoms. Triazoles and their derivatives have been proved effective bacteriocides ${ }^{2}$, pesticides ${ }^{3}$, fungicides $^{4-5}$ and insecticides ${ }^{6-7}$. The Schiff base acts as a bidentate monobasic donor for $\mathrm{Cu}(\mathrm{II}), \mathrm{Co}(\mathrm{II}), \mathrm{Ni}$ (II) $\mathrm{Mn}$ (II) and $\mathrm{Fe}(\mathrm{III})$ and prominent sites of coordination are nitrogen of the azomethine group and oxygen of the hydroxyl group. Thus the present study describes the synthetic and structural studies of bivalent transition metal $\mathrm{Cu}(\mathrm{II}), \mathrm{Co}(\mathrm{II}), \mathrm{Ni}$ (II), $\mathrm{Mn}$ (II) and Fe(III) complexes of Schiff base derived from 3-(4-Chlorophenoxymethyl)-4-amino-5mercapto-1,2,4-triazole with salicylaldehyde. The survey of literature reveals that no work has been carried out on the synthesis of the ligand (CITHS) and its metal complexes.

\section{Experimental}

All the reagents /chemicals were of reagent grade. Solvents were dried and distilled before use according to standard procedures ${ }^{8}$. The precursor 3-(4-chlorophenoxymethyl)-4-amino-5mercapto-1, 2, 4-triazole was prepared by literature $\operatorname{method}^{9}$. The metal chlorides / salts used were in their hydrated form.

Infrared spectra of the synthesized ligand and its metal complexes were recorded as on Perkin Elmer 1000 FT-IR spectrometer using KBr pellets. UV-Visible spectra were recorded on an Elico SL-164 DOUBLE BEAM UV-Vis. spectrophotometer in the range of 200-1200 nm. Magnetic susceptibilities were determined by the Faraday method using a model 300 Lewis coil Force Magnetometer of Tesla strength at room temperature. The instrument was calibrated ${ }^{10}$ using $\mathrm{HgCo}(\mathrm{NCS})_{4}$. The molar conductance of the complexes were measured on ELICO CM-82 conductivity Bridge in DMF solution $\left(1 \times 10^{-3} \mathrm{M}\right) .{ }^{1} \mathrm{H}$ NMR spectra were recorded on AMX-400 NMR spectrometer, using TMS as internal standard and DMSO as a solvent. ESR measurements were carried out on a BRUKER Biospin Gmbh spectrometer working at a microwave frequency of $9.1 \mathrm{GHz}$. The experiment was carried out by using diphenylpicrylhydrazyl (DPPH) as reference with the field at 3200 Gauss. The CHN elemental analyses were determined using a Perkin-Elmer micro elemental analyzer. The metal chloride analysis was carried out by the following standard method. Sulphur ${ }^{11}$ in the complexes estimated as $\mathrm{BaSO}_{4}$.

\section{Synthesis of ligand (ClTHS)}

A mixture of 3-(4-chlorophenoxymethyl)-4-amino-5-mercapto-1, 2, 4-triazole and salicyladehyde in 1:1 molar proportions in alcoholic medium containing a few drops of concentrated hydrochloric acid, was refluxed for $4 \mathrm{~h}$ on a steam bath. The reaction mixture was cooled to room temperature. The Schiff base 2-[(E)-(\{3-[(4-chlorophenoxy)methyl]-5mercapto-4H-1,2,4-triazol-4-yl\}imino]phenol(ClTHS) separated was filtered, washed and recrystallized from alcohol.

\section{Synthesis of complexes}

To the hot solutions of the ligand CITHS $(0.01 \mathrm{~mol})$ in ethanol $(35 \mathrm{~mL})$, a hot ethanolic solution of respective metal chlorides in ethanol $(15 \mathrm{~mL})$ was added and reaction mixture was then treated with sodium acetate $(0.5 \mathrm{~g})$ just to adjust the $\mathrm{pH}$ of the solution. The reaction mixture was further refluxed for $2 \mathrm{~h}$. The resulting mixture decomposed by pouring into the $100 \mathrm{~mL}$ distilled water with stirring. The suspended solid complex was allowed to settle and collected by filtration, washed with sufficient quantity of distilled water and then with little hot ethanol to apparent dryness and dried in a vacuum over anhydrous calcium chloride in a desiccators. The yield was $70 \%$. 
<smiles>Nn1c(S)nnc1COc1ccc(Cl)cc1</smiles>

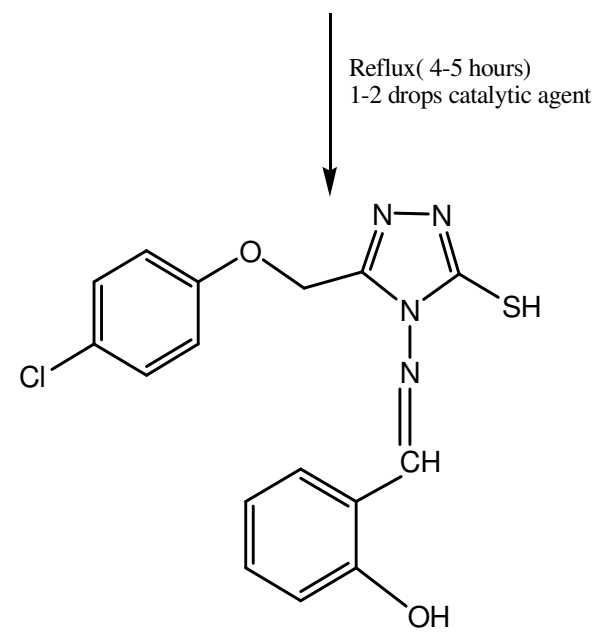

Figure 1. 2-[(E)-(\{3-[(4-chlorophenoxy)methyl]-5-mercapto-4H-1,2,4-triazol-4-yl $\}$ imino] phenol (CITHS).

\section{Results and Discussion}

The elemental analysis shown in Table 1 indicates that, all the metal complexes have 1:2 stoichiometry and are dark colored amorphous substances, soluble in DMF and DMSO. The molar conductance values obtained for these complexes at the concentration of $10^{-3} \mathrm{M}$ are in the range of $20-30 \mathrm{ohm}^{-1} \mathrm{~mol}^{-1} \mathrm{~cm}^{2}$. These values are too low to account for any dissociation of the complexes in DMF. Hence these complexes can be regarded as non-electrolytes ${ }^{12}$.

\section{Magnetic susceptibility}

The magnetic moment values for $\mathrm{Cu}(\mathrm{II}), \mathrm{Co}(\mathrm{II}), \mathrm{Ni}(\mathrm{II}), \mathrm{Mn}$ (II) and $\mathrm{Fe}(\mathrm{III})$ complexes of the ligand ClTHS are shown in Table1. The magnetic moment for $\mathrm{Cu}(\mathrm{II})$ complex is $1.94 \mathrm{BM}$. The reported values for the mononuclear $\mathrm{Cu}$ (II) complex having no major spin interactions $(1.75-2.20 \mathrm{BM})^{13,14}$. Thus the present $\mathrm{Cu}$ (II) complex is devoid of any spin interaction with octahedral geometry. In octahedral $\mathrm{Cu}$ (II) complex the ground state is ${ }^{4} \mathrm{~T}_{1 \mathrm{~g}}$ and large orbital contribution to the magnetic moment is expected. The mixing of the singlet states lowers the magnetic moments of $\mathrm{Co}$ (II) complexes are in the range of 5.05-5.14 BM indicating that the Co(II) complexes are typically high spin complexes and having octahedral structure ${ }^{15}$. For $\mathrm{Ni}$ (II) complex the observed magnetic moment value is $2.94 \mathrm{BM}$ which is well within the expected range for $\mathrm{Ni}(\mathrm{II})$ complex with octahedral stereochemistry $(2.83-4.0 \mathrm{BM})^{16,17}$. The complexes of $\mathrm{Mn}$ (II) and $\mathrm{Fe}$ (III) values exhibited the magnetic moments of $5.70 \mathrm{BM}$ and $5.86 \mathrm{BM}$ respectively ${ }^{18,19}$, indicating it to be high-spin type paramagnetic, it lies within the octahedral range which very close to spin only value of $5.90 \mathrm{BM}$ as the ground term is ${ }^{6} \mathrm{~A}_{1 \mathrm{~g}}$ and thus supports the octahedral stereochemistry ${ }^{20}$. 
Table 1. Physical, analytical, magnetic susceptibility and molar conductance data of the ligand ClTHS and its complexes

\begin{tabular}{|c|c|c|c|c|c|c|c|c|c|c|c|c|}
\hline $\begin{array}{l}\text { Ligand / } \\
\text { Complex }\end{array}$ & $\begin{array}{c}\text { Empirical } \\
\text { Formula }\end{array}$ & $\begin{array}{l}\text { Mol. } \\
\text { Wt. }\end{array}$ & ${ }^{\mathrm{M} . \mathrm{P}} \mathrm{C}$ & $\begin{array}{l}\text { Yield } \\
\%\end{array}$ & $\mathrm{M}$ & $\mathrm{C}$ & $\mathrm{H}$ & $\mathrm{N}$ & $S$ & $\mathrm{Cl}$ & $\begin{array}{c}\mu_{\mathrm{ef}} \\
\text { B.M. }\end{array}$ & $\begin{array}{l}\text { Molar Conductance } \\
\wedge \mathrm{m} \mathrm{Ohm}^{-1} \mathrm{~cm}^{2} \mathrm{~mol}^{-1}\end{array}$ \\
\hline CITHS & $\mathrm{C}_{16} \mathrm{H}_{13} \mathrm{~N}_{4} \mathrm{O}_{2} \mathrm{SCl}$ & 360.82 & 190 & 65 & - & $\begin{array}{c}53.31 \\
(53.26)\end{array}$ & $\begin{array}{c}3.62 \\
(3.63)\end{array}$ & $\begin{array}{c}15.52 \\
(15.53)\end{array}$ & $\begin{array}{c}8.89 \\
(8.85)\end{array}$ & $\begin{array}{l}9.81 \\
(9.83)\end{array}$ & - & - \\
\hline $\mathrm{CuL}_{2}\left(2 \mathrm{H}_{2} \mathrm{O}\right)$ & $\mathrm{C}_{32} \mathrm{H}_{28} \mathrm{Cl}_{2} \mathrm{CuN}_{8} \mathrm{O}_{6} \mathrm{~S}_{2}$ & 819.2 & 297 & 60 & $\begin{array}{c}7.71 \\
(7.76)\end{array}$ & $\begin{array}{c}46.95 \\
(46.92)\end{array}$ & $\begin{array}{c}3.41 \\
(3.45)\end{array}$ & $\begin{array}{l}13.70 \\
(13.68)\end{array}$ & $\begin{array}{c}7.84 \\
(7.83)\end{array}$ & $\begin{array}{c}8.65 \\
(8.66)\end{array}$ & 1.94 & 17.15 \\
\hline $\mathrm{CoL}_{2}\left(2 \mathrm{H}_{2} \mathrm{O}\right)$ & $\mathrm{C}_{32} \mathrm{H}_{28} \mathrm{Cl}_{2} \mathrm{CoN}_{8} \mathrm{O}_{6} \mathrm{~S}_{2}$ & 814.6 & 280 & 65 & $\begin{array}{c}7.20 \\
(7.23)\end{array}$ & $\begin{array}{c}47.15 \\
(47.18)\end{array}$ & $\begin{array}{c}3.42 \\
(3.46)\end{array}$ & $\begin{array}{c}13.77 \\
(13.76)\end{array}$ & $\begin{array}{c}7.86 \\
(7.87)\end{array}$ & $\begin{array}{c}8.71 \\
(8.70)\end{array}$ & 5.15 & 17.38 \\
\hline $\mathrm{NiL}_{2}\left(2 \mathrm{H}_{2} 0\right)$ & $\mathrm{C}_{32} \mathrm{H}_{28} \mathrm{Cl}_{2} \mathrm{NiN}_{8} \mathrm{O}_{6} \mathrm{~S}_{2}$ & 814.3 & 275 & 64 & $\begin{array}{c}7.22 \\
(7.21)\end{array}$ & $\begin{array}{c}47.17 \\
(47.20)\end{array}$ & $\begin{array}{c}3.45 \\
(3.47)\end{array}$ & $\begin{array}{c}13.75 \\
(13.76)\end{array}$ & $\begin{array}{c}7.81 \\
(7.88)\end{array}$ & $\begin{array}{c}8.69 \\
(8.71)\end{array}$ & 2.94 & 19.89 \\
\hline $\mathrm{MnL}_{2}\left(2 \mathrm{H}_{2} \mathrm{O}\right)$ & $\mathrm{C}_{32} \mathrm{H}_{28} \mathrm{Cl}_{2} \mathrm{MnN}_{8} \mathrm{O}_{6} \mathrm{~S}_{2}$ & 810.6 & $>300$ & 60 & $\begin{array}{c}6.75 \\
(6.78)\end{array}$ & $\begin{array}{c}47.43 \\
(47.42)\end{array}$ & $\begin{array}{c}3.47 \\
(3.48)\end{array}$ & $\begin{array}{c}13.80 \\
(13.82)\end{array}$ & $\begin{array}{c}7.95 \\
(7.91)\end{array}$ & $\begin{array}{c}8.73 \\
(8.75)\end{array}$ & 5.70 & 15.13 \\
\hline $\mathrm{FeL}_{2}\left(\mathrm{H}_{2} 0\right) \mathrm{Cl}$ & $\mathrm{C}_{32} \mathrm{H}_{26} \mathrm{Cl}_{3} \mathrm{FeN}_{8} \mathrm{O}_{5} \mathrm{~S}_{2}$ & 828.9 & 285 & 65 & $\begin{array}{c}7.71 \\
(6.74)\end{array}$ & $\begin{array}{c}46.35 \\
(46.37)\end{array}$ & $\begin{array}{c}3.14 \\
(3.16)\end{array}$ & $\begin{array}{c}16.55 \\
(16.52)\end{array}$ & $\begin{array}{c}7.70 \\
(7.74)\end{array}$ & $\begin{array}{l}12.81 \\
(12.8)\end{array}$ & 5.86 & 18.26 \\
\hline
\end{tabular}




\section{Electronic spectra}

The electronic spectral data of $\mathrm{Cu}(\mathrm{II}), \mathrm{Co}(\mathrm{II}), \mathrm{Ni}(\mathrm{II}), \mathrm{Mn}$ (II) and $\mathrm{Fe}(\mathrm{III})$ complexes of the ligand ClTHS were recorded in DMF as shown in Table 2 . The light green colored $\mathrm{Cu}$ (II) complex exhibit a broad asymmetric band in the region $12275-16262 \mathrm{~cm}^{-1}$ with maxima at $14265 \mathrm{~cm}^{-1}$ in an distorted octahedral geometry ${ }^{21}$. The broadness of the band may be due to dynamic JahnTeller distortion and is assigned to ${ }^{2} \mathrm{~T}_{2 \mathrm{~g}} \rightarrow{ }^{2} \mathrm{E}_{\mathrm{g}}$ transitions. In the electronic spectra of Co(II) complex the three absorption bands observed at $10055 \mathrm{~cm}^{-1}, 16005 \mathrm{~cm}^{-1}$ and $20345 \mathrm{~cm}^{-1}$, due to ${ }^{4} \mathrm{~T}_{2 \mathrm{~g}}(\mathrm{~F}) \rightarrow{ }^{4} \mathrm{~A}_{2 \mathrm{~g}}\left(\mathrm{v}_{1}\right),{ }^{4} \mathrm{~T}_{1 \mathrm{~g}}(\mathrm{~F}) \rightarrow{ }^{4} \mathrm{~A}_{2 \mathrm{~g}}(\mathrm{~F})\left(\mathrm{v}_{2}\right)$, and ${ }^{4} \mathrm{~T}_{1 \mathrm{~g}}(\mathrm{~F}) \rightarrow{ }^{4} \mathrm{~T}_{1 \mathrm{~g}}(\mathrm{P})\left(\mathrm{v}_{3}\right)$ transitions respectively. These transition suggest octahedral geometry for Co(II) complex ${ }^{22,23}$ These assignments are in good agreement with the reported value ${ }^{24,25}$. The ligand field parameters such as Dq, B', $\beta$ and $\beta \%$ have been calculated by using band-fitting equation given by Underhill and Billing ${ }^{26}$. The crystal field splitting energy (Dq) value was found to be $846 \mathrm{~cm}^{-1}$. These values are well within the range reported are most of the octahedral $\mathrm{Co}$ (II) complexes. The Co(II) complex under present investigation process interelectronic repulsion parameter (B') $917 \mathrm{~cm}^{-1}$. The Racha parameter (B') is less than free ion value 971 suggesting a considerable orbital overlap and delocalization of electrons on the metal ion. The nephelauxetic ratio ( $\beta$ ) for the present $\mathrm{Co}(\mathrm{II})$ complex 0.94 which is less than one, suggesting partial covalency in the metal ligand bond. The values Dq, $\beta \%$, LFSE, $v_{2} / v_{1}$ (Table 2) suggest the octahedral geometry for Co(II) complex ${ }^{27}$. Ni(II)complexes exhibit three bands at $10870 \mathrm{~cm}^{-1}, 15270 \mathrm{~cm}^{-1}$ and $25645 \mathrm{~cm}^{-1}$ are assigned to ${ }^{3} \mathrm{~A}_{2 \mathrm{~g}}(\mathrm{~F}) \rightarrow{ }^{3} \mathrm{~T}_{2 \mathrm{~g}}(\mathrm{~F})$ $\left(v_{1}\right),{ }^{3} \mathrm{~A}_{2 \mathrm{~g}}(\mathrm{~F}) \rightarrow{ }^{3} \mathrm{~T}_{1 \mathrm{~g}}(\mathrm{~F})\left(v_{2}\right)$ and ${ }^{3} \mathrm{~A}_{2 \mathrm{~g}}(\mathrm{~F}) \rightarrow{ }^{3} \mathrm{~T}_{1 \mathrm{~g}}(\mathrm{p})\left(v_{3}\right)$ transitions respectively are in confirmatory with the octahedral geometry for the $\mathrm{Ni}(\mathrm{II})$ ion. The Table 2 shows the ligand field parameter such as Dq, B', $\beta, \beta \%$ and LFSE have been calculated by using Band-fitting equation given by Underhill and Billing ${ }^{26}$. Racah parameter $\mathrm{B}^{\prime}$ is less than the free ion value of $1040 \mathrm{~cm}^{-1}$ indicating the covalent character of the complex. Moreover, the ratio $v_{2} / v_{1}$ was found to be 1.4046 which is well which the range $(1.40-1.61)$ and is indicative of octahedral stereochemistry for this $\mathrm{Ni}$ (II) complex ${ }^{28}$.The lowest band $v_{2}(10 \mathrm{Dq})$ was not observed due to limited range of the instrument used. However, it is calculated by using equation suggested by Billing and Underhill ${ }^{26}$. The Racha parameter $\mathrm{B}^{1}$ is $852 \mathrm{~cm}^{-1}$, which is less than the free ion value of $1040 \mathrm{~cm}^{-1}$ indicating the covalent character of the $\mathrm{Ni}(\mathrm{II})$ complex. The ratio $v_{2} / v_{1}(1.4)$ and $\beta \%$ (17.98) supports the octahedral geometry around the $\mathrm{Ni}$ (II) ion ${ }^{29}$. The $\mathrm{Mn}(\mathrm{II})$ complex observed bands at $12830-19275 \mathrm{~cm}^{-1}$ due to the transition ${ }^{6} \mathrm{~A}_{1 \mathrm{~g}} \rightarrow{ }^{4} \mathrm{~T}_{1 \mathrm{~g}}, \quad{ }^{6} \mathrm{~A}_{1 \mathrm{~g}} \rightarrow{ }^{4} \mathrm{~T}_{2 \mathrm{~g}}(\mathrm{G})$ and ${ }^{6} \mathrm{~A}_{1 \mathrm{~g}} \rightarrow{ }^{4} \mathrm{Eg}(\mathrm{G})$ suggest the high spin octahedral geometry around the metal ion ${ }^{30,31}$. The Fe(III) complex observed band at 17556-29590 $\mathrm{cm}^{-1}$ due to the transitions ${ }^{6} \mathrm{~A}_{1 \mathrm{~g}} \rightarrow{ }^{4} \mathrm{~T}_{1 \mathrm{~g}},{ }^{6} \mathrm{~A}_{1 \mathrm{~g}} \rightarrow{ }^{4} \mathrm{~T}_{2 \mathrm{~g}}(\mathrm{G})$ and ${ }^{6} \mathrm{~A}_{1 \mathrm{~g}} \rightarrow{ }^{4} \mathrm{E}_{\mathrm{g}}(\mathrm{G})$ respectively suggest the high spin octahedral geometry around the metal ion ${ }^{32,33}$.

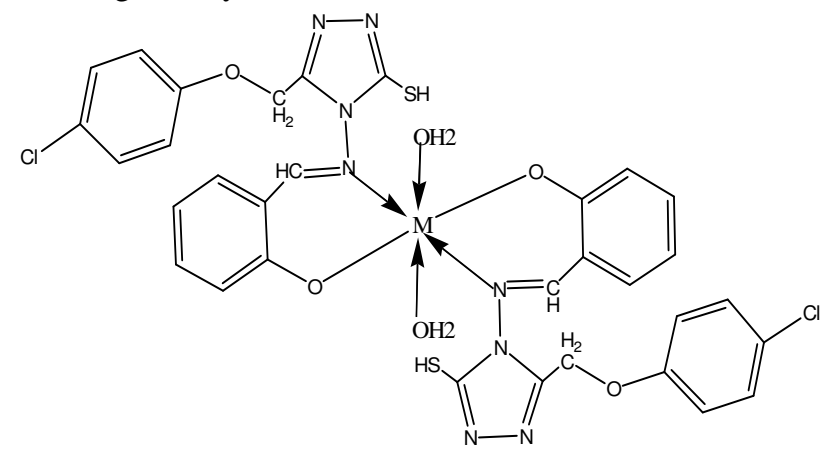

Where $\mathrm{M}=\mathrm{Cu}(\mathrm{II}), \mathrm{Co}(\mathrm{II}), \mathrm{Ni}(\mathrm{II})$ and $\mathrm{Mn}(\mathrm{II})$

Figure 2. Probable structure of complexes of the ligand ClTHS. 


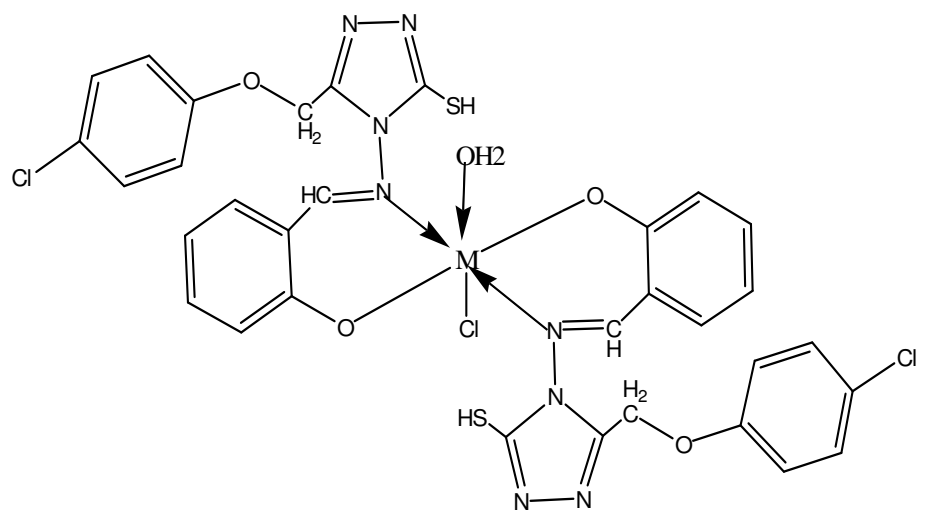

Where $\mathrm{M}=\mathrm{Fe}(\mathrm{III})$

Figure 3. Probable structure of Fe(III) complex of the ligand ClTHS.

Table 2. Electronic spectral data and ligand field parameters of $\mathrm{Cu}(\mathrm{II}), \mathrm{Co}(\mathrm{II}), \mathrm{Ni}(\mathrm{II})$ and $\mathrm{Fe}(\mathrm{III})$ complexes

\begin{tabular}{cccccccccc}
\hline Complexes & $v_{1}$ & $v_{2}$ & $v_{3}$ & $\begin{array}{c}\mathrm{Dq} \\
\mathrm{cm}^{-1}\end{array}$ & $\mathrm{~B}^{1}$ & $\beta$ & $\beta \%$ & $v_{2} / v_{1}$ & $\begin{array}{c}\mathrm{LFSE} \\
\mathrm{kcal} \mathrm{mol}^{-1}\end{array}$ \\
\hline $\mathrm{CuL}_{2}\left(2 \mathrm{H}_{2} \mathrm{O}\right)$ & 12275 & 16262 & - & 1426 & - & - & - & 1.3 & 24.44 \\
$\mathrm{CoL}_{2}\left(2 \mathrm{H}_{2} \mathrm{O}\right)$ & 10055 & 16005 & 20345 & 847 & 917 & 0.94 & 5.60 & 1.5 & 14.50 \\
$\mathrm{NiL}_{2}\left(2 \mathrm{H}_{2} \mathrm{O}\right)$ & 10870 & 15270 & 25645 & 937 & 852 & 0.82 & 17.9 & 1.4 & 32.13 \\
$\mathrm{MnL}_{2}\left(2 \mathrm{H}_{2} \mathrm{O}\right)$ & 12005 & 17015 & 19000 & 896 & 790 & 0.74 & 25.09 & 1.4 & 15.36 \\
$\mathrm{FeL}_{2}\left(\mathrm{H}_{2} \mathrm{O}\right) \mathrm{Cl}$ & 12910 & 15987 & 19635 & 838 & 854 & 0.80 & 19.05 & 1.2 & 14.36 \\
\hline
\end{tabular}

\section{Infrared spectra}

The important infrared frequencies exhibited by the ligand CITHS and its complexes are given in Table 3 . The ligand do exhibit tautomerism ${ }^{34}$ and one can expect both $v_{\mathrm{S}-\mathrm{H}}$ and $v_{\mathrm{C}=\mathrm{S}}$. A medium intensity band around $2523 \mathrm{~cm}^{-1}$ due to $v_{\mathrm{S}-\mathrm{H}}$ indicates the thiol form of the ligand. The band due to $v_{\mathrm{C}=\mathrm{S}}$ in the $780-740 \mathrm{~cm}^{-1}$ of the ligands has remained unperturbed in these complexes indicating that $\mathrm{N}$ or $\mathrm{S}$ of the thiamide group is not involved in the bond formation ${ }^{35}$ These observations suggest the non-involvement of sulfur atom in coordination. The infrared spectra of ligands exhibits high intensity band around $1617 \mathrm{~cm}^{-1}$ is due to $v_{\mathrm{C}=\mathrm{N}}$. In the complexes, this band shifted to lower frequency $\left(15-20 \mathrm{~cm}^{-1}\right)$ around $1602 \mathrm{~cm}^{-1}$ is suggestive of coordination through nitrogen of the azomethine group ${ }^{36-38}$, to the metal(II) chlorides. The band observed in the region $1284 \mathrm{~cm}^{-1}$ for $v_{\mathrm{C}-\mathrm{O}}$ stretching vibrations undergoes shift to higher wave number at 1310 to $1377 \mathrm{~cm}^{-1}$ compared with free ligand band. The band around $3332 \mathrm{~cm}^{-1}$ due to phenolic $\mathrm{OH}$, which is observed in ligand, disappears in complexes, this indicates the ligand co-ordinate to the metal ion through phenolic oxygen atom ${ }^{39}$ of $\mathrm{OH}$ group via deprotonation. A broad band appeared in the region $3443-3523 \mathrm{~cm}^{-1}$ in all complexes complexes indicates the presence of coordinated water or lattice water ${ }^{40}$. The participation of oxygen and nitrogen in coordination with the metal ion is further supported by the new band appearance of $v_{\mathrm{M}-\mathrm{N}}$ and $v_{\mathrm{M}-\mathrm{O}}$ at $550-520 \mathrm{~cm}^{-1}$ and $380-420 \mathrm{~cm}^{-}$ 1 , respectively in the far infrared region ${ }^{41-44}$. The bands in the region $320-325 \mathrm{~cm}^{-1}$ have been assigned to $v_{\mathrm{M}-\mathrm{Cl}}$ bands in all the complexes ${ }^{45}$. The presence of chlorine atoms in all the complexes is further confirmed by quantitative chloride estimation. 
Table 3.Characteristic IR frequencies $\left(\mathrm{cm}^{-1}\right)$ of the ligand CITHS and its complexes

\begin{tabular}{cccccccccc}
\hline $\begin{array}{l}\text { Ligand/ } \\
\text { complexes }\end{array}$ & $v_{\mathrm{H} 2 \mathrm{O}}$ & $v_{\mathrm{OH}}$ & $v_{\mathrm{SH}}$ & $v_{\mathrm{C}=\mathrm{S}}$ & $v_{\mathrm{C}=\mathrm{N}}$ & $v_{\mathrm{C}-\mathrm{O}}$ & $v_{\mathrm{M}-\mathrm{O}}$ & $v_{\mathrm{M}-\mathrm{N}}$ & $v_{\mathrm{M}-\mathrm{Cl}}$ \\
\hline $\mathrm{ClTHS}$ & - & 3332 & 2523 & 780 & 1617 & 1289 & - & - & - \\
$\mathrm{CuL}_{2}\left(2 \mathrm{H}_{2} \mathrm{O}\right)$ & 3420 & - & 2523 & 778 & 1596 & 1353 & 412 & 520 & - \\
$\mathrm{CoL}_{2}\left(2 \mathrm{H}_{2} \mathrm{O}\right)$ & 3451 & - & 2523 & 772 & 1603 & 1355 & 380 & 526 & - \\
$\mathrm{NiL}_{2}\left(2 \mathrm{H}_{2} \mathrm{O}\right)$ & 3470 & - & 2523 & 776 & 1602 & 1362 & 405 & 532 & - \\
$\mathrm{MnL}_{2}\left(2 \mathrm{H}_{2} \mathrm{O}\right)$ & 3495 & - & 2523 & 779 & 1603 & 1310 & 420 & 546 & - \\
$\mathrm{FeL}_{2}\left(\mathrm{H}_{2} \mathrm{O}\right) \mathrm{Cl}$ & 3433 & - & 2523 & 770 & 1598 & 1377 & 415 & 550 & 320 \\
\hline
\end{tabular}

${ }^{1} H$ NMR Spectra of ligand ClTHS

The ${ }^{1} \mathrm{H}$ NMR spectrums of ligand CITHS shows multiplets were observed around $86.9-8.62$ $(\mathrm{m} .8 \mathrm{H}, \mathrm{Ar}-\mathrm{H})$ are due to phenyl protons. A proton due to -OH group at 2-position of salicylaldehyde ring has resonated as a singlet at $\delta 12.00(\mathrm{~S} .1 \mathrm{H}, \mathrm{OH})$ and a signal at $\delta 3.32$ due to $\left(\mathrm{ArO}-\mathrm{CH}_{2}\right.$ protons, signal due to $(\mathrm{S}, 1 \mathrm{H}, \mathrm{HC}=\mathrm{N})$ resonated at $\delta 8.4$. Signals in the range of $\delta$ 9.6-10 $(\mathrm{S} 1 \mathrm{H}, \mathrm{SH})$ are due to $\mathrm{SH}$ protons ${ }^{46}$. This shows that the ligand exists in thiol form rather than in thione ${ }^{47}$ form, which supports IR observation.

\section{${ }^{1} H$ NMR Spectra of Zn(II) complex}

In its ${ }^{1} \mathrm{H}$ NMR spectrum, the sixteen aromatic protons have resonated in the region $87.2-842$ $(\mathrm{m}, 16,16 \mathrm{X} \mathrm{H})$ as a multiplet. The signal due to $\mathrm{OH}$ at $\delta 12.00$ in ligand, disappears in case of complexes indicating the involvement of $\mathrm{OH}$ in the complexes formation via deprotonation. The $\mathrm{HC}=\mathrm{N}$, proton signal appears at $\delta 8.8$ the downfield shift in the complex indicate that the desheilding due to coordination of $\mathrm{C}=\mathrm{N}$ group through nitrogen. The signal due to SH proton appears unperturbed in the complexes indicates the non-involvement of sulfur atom of $\mathrm{SH}$ group.

\section{ESR spectra}

The ESR spectra of the polycrystalline sample of the complexes were recorded at room temperature Table 4 . The observed value for the $\mathrm{Cu}(\mathrm{II})$ complex for the ligand. The anisotropic $\mathrm{G}$ values have been calculated by Kneubuhl'smethod ${ }^{48} . G=\left(g_{\|}-2\right) /\left(g_{\perp}-2\right)$ which measures the exchange interaction between copper(II) centers. According to Hathaway ${ }^{49}$ if the $G$ value is greater than 4 , the exchange interaction is negligible, while a value of less than 4 indicates a considerable exchange interaction in the complexes. One unpaired electron in $\mathrm{Cu}$ (II) complex with ${ }^{2} \mathrm{~B}_{1 \mathrm{~g}}$ as ground state lies in $\mathrm{d}_{\mathrm{x} 2 \mathrm{y} 2}$ spectrum of $\mathrm{Cu}$ (II) complex of ligand orbital and follows the trend $g_{\|}>g_{\perp}>g_{e}\left(g_{e}=2.0036\right.$ free ion value $)$. The observed $g_{\|}=2.257$ and $g_{\perp}=2.059$ values of the $\mathrm{Cu}$ (II) complex under present study followed the same trend $\mathrm{g}_{\|}>\mathrm{g}_{\perp}>\mathrm{g}_{\mathrm{e}}$ which suggest that the presence of unpaired electron $d_{x 2-y 2}$ orbital giving octahedral geometry ${ }^{50}$. The observed $G=$ 4.4 for the complex under present study evidenced the monomeric nature of the complex ${ }^{51}$ and indicates that there is no spin exchange interaction in the copper complexes and hence distorted octahedral geometry proposed for the $\mathrm{Cu}$ (II) complex.

Table 4. ESR data of the $\mathrm{Cu}$ (II) complex of the ligand ClTHS

\begin{tabular}{cccccc}
\hline Complex & $\mathrm{g}_{\|}$ & $\mathrm{g}_{\perp}$ & $\mathrm{g}_{\mathrm{av}}$ & $\mathrm{g}_{\text {iso }}$ & $\mathrm{G}$ \\
\hline $\mathrm{CuL}_{2}\left(2 \mathrm{H}_{2} \mathrm{0}\right)$ & 2.257 & 2.059 & 2.12 & 2.20 & 4.4 \\
\hline
\end{tabular}




\section{Antimicrobial activity}

The synthesized CITHS ligand and its complexes were screened for their antibacterial activity $^{52}$ against $E$. coli and $S$. aurious and antifungal activity against ${ }^{53}$ A. niger and A. flavous at $100 \mu \mathrm{g} / 0.1 \mathrm{~cm}^{3}$ concentration The standard drugs streptomycin and clotrimazole were also tested for their antibacterial and antifungal activity at the same concentration under the conditions similar to that of the test compounds concentration. The zones of inhibitions of the antimicrobial activity have been presented in Table 5 . The results of antibacterial activity of ligands and its complexes $\mathrm{Cu}$ (II), $\mathrm{Co}$ (II) and $\mathrm{Ni}$ (II) shows weak activity against $E$. coli and $S$. aurious when compared with standard Streptomycin. The antifungal activity results revealed that the ligands and its $\mathrm{Cu}(\mathrm{II})$, $\mathrm{Co}(\mathrm{II})$ and $\mathrm{Ni}$ (II), complexes have exhibited weak to good activity against $A$. niger and A. flavous. The ligand and its $\mathrm{Cu}(\mathrm{II})$ and $\mathrm{Co}$ (II) complexes shows weak activity when compared to the standard drug clotrimazole .

Table 5. Antimicrobial activity of the ligands CITHS and its complexes

\begin{tabular}{lcccc}
\hline \multirow{2}{*}{ Compound } & \multicolumn{2}{c}{$\begin{array}{c}\text { Antibacterial Activity of zone of } \\
\text { inhibition (in mm) }\end{array}$} & $\begin{array}{c}\text { Antifungal Activity of zone } \\
\text { of inhibition, mm }\end{array}$ \\
\cline { 2 - 5 } & E. coli & S. aureus & A. niger & A. falvous \\
\hline Ligand ClTHS & 13 & 13 & 11 & 13 \\
$\mathrm{CuL}_{2}\left(2 \mathrm{H}_{2} 0\right)$ & 16 & 15 & 14 & 17 \\
$\mathrm{CoL}_{2}\left(2 \mathrm{H}_{2} 0\right)$ & 15 & 18 & 14 & 15 \\
$\mathrm{NiL}_{2}\left(2 \mathrm{H}_{2} 0\right)$ & 16 & 14 & 18 & 17 \\
$\mathrm{MnL}_{2}\left(2 \mathrm{H}_{2} 0\right)$ & 15 & 15 & 13 & 16 \\
$\mathrm{FeL}_{2}\left(\mathrm{H}_{2} 0\right) \mathrm{Cl}$ & 17 & 16 & 16 & 14 \\
Streptomycin & 24 & 21 & 24 & 23 \\
Clotrimazole & - & - & - & - \\
DMF (Control) & 0 & 0 & 0 & 0 \\
Bore size & 08 & 08 & 08 & 0 \\
\hline
\end{tabular}

\section{Conclusions}

The ligand 2-[(E)-(\{3-[(4-chlorophenoxy) methyl]-5-mercapto-4H-1, 2, 4-triazol-4-yl $\}$ imino] phenol behaved as a monobasic bidentate coordinating through ' $\mathrm{N}$ ' and ' $\mathrm{O}$ ' of $\mathrm{OH}$ group. Analytical data, electronic spectra, magnetic susceptibility, IR, ${ }^{1} \mathrm{HNMR}$, ESR spectral data reveal octahedral geometry for all the complexes. The low conductance values show non-electrolytic behavior of the complexes. The ligand [CITHS] and its all complexes were tested for antimicrobial activity. The complexes are shows moderate to good antibacterial and antifungal activity compared to its ligand. On the basis of spectral evidence, the following probable structures have been assigned for synthesized compounds.

\section{Acknowledgements}

The authors are thankful to Dr. S.D. Angadi, Professor and Chairman, Department of Studies and Research in Chemistry, Gulbarga University, Gulbarga for providing the necessary facilities. Thanks are also to Chairman, Department of Microbiology and Department of Botany, Gulbarga University, Gulbarga for carrying antimicrobial activities. They also thank IISc Bangalore, STIC Cochin, SAIF Lacknow, IIT Bombay, and Central Instrumentation Centre, Central University, Hyderabad for providing ${ }^{1} \mathrm{H}$ NMR, CHN analysis, and ESR spectra. 


\section{References}

1 Antloin L, Febretel A C, Galtesti D, Giushi A and Sessoli R, Inorg. Chem,1990, 29,143.

2 Shymal A and Bari Niazi M.A, Indian J. Chem, 1984, 23A, 163.

3 Sengupta A K, Bajaj V P and Chandra U, J Indian Chem. Soc, 1978, 55,962.

4 Singh H, Yadav L D S and Bhattacharya B K, J. Indian Chem. Soc., 1979, 56, 1013.

5 Giri S, Singh H, Yadav L D S and Khare R K, J Indian Chem. Soc.,1978, 55,168.

$6 \quad$ Rao S and Mittra A S, Indian J. Chem. Sect B, 1977, 15, 1062.

7 Tanara G, Japan kokai, 1974, 973, 7495.

8 Vogel A I, A Text book of Quantitative Organic Analysis; $3^{\text {rd }}$ Ed., ELBS Longmans Green and Co. Ltd, 1962.

9 Patel K D, Mistry B D and Desai K R, J. Indian Chem. Soc, 2002, 79, 964-965.

10 Connor C J, Sinn E S, Cukaskas E J and Deaver B S, Inorg. Chim. Acta, 1979, 32, 29.

11 Maurya R C, Mishra D D, Gohe R K and Khan I B, J. Indian Chem. Soc, 1990, 68, 235

12 Geary W J, Coord. Chem. Rev, 1972, 1, 81.

13 Giusberg A P, Inorg. Chim. Acta. Rev, 1972, 5, 45.

14 Angela Kriza, Cezar Spinu and Mario Pleniceanu, J. Indian Chem. Soc., 2001, 77, 645.

15 Figgis B N and Lewis J, Progress in Inorganic Chemistry Edited by Cotton, F.A. $6^{\text {th }}$ Ed., Interscience, New York, 1964.

16 Ketan Patel M, Patel N H, Patel K N and Patel M N, J. Indian Council Chemists, 2000, 17, 19.

17 Bekhet M M and Ibrahim K M, Synth. React. Inorg. Met. Org. Chem, 1986, 16, 1135.

18 Singh T and Singh R N, Synth. React. Inorg. Met. Org. Chem, 1989, 19(3), 251.

19 Sulekh Chandra and Lokesh K G, J. Indian Chem. Soc, 2004, 81,739

20 Koji Abe, Konako, Matsufuji, Maseakiohba and Hisashi Okawa, Inorg. Chem, 2002, 41, 4461.

21 Lever A B P, Inorganic Electronic Spectroscopy; Elsevier, New York 1984.

22 Sulekha Chandra and Gupta K, Indian J. Chem. 2001, 40A, 775.

23 (a) Verma J K and Verma G S P, Indian J. Chem, 1982, 21A, 825;(b) Lakshumi and Rai R A, J. Inorg. Nucl. Chem, 1984, 42, 450.

24 Satpathy K C, Jal B B and Mishra R, Trans. Met. Chem, 1984, 9, 8.

25 Underhill A E and Billing D, Nature.1996, 210, 834.

26 Lever A B P, Inorganic Spectroscopy; Elsevier, Amsterdam, 1968.

27 Figgs B N, Introduction to Ligand Fields; Interscience John-wiley and Sons, New York, 1967.

28 Makode J T and Aswar A S, J. Indian Chem. Soc. 2003, 80, 44-46.

29 Mohamed G G, Spectrochim Acta, 2001, 57(A), 1643

30 Abu El-Reash, Ibrahim K M and Bekheit M M, Bull. Soc. Chim. Fr.,1991, 128,149

31 Narang K K and Singn V P, Synth. React. Inorg. Met-Org. Chem., 1993, 23,971

32 Srivastava A K, Rana V B and Mohan M, J. Inorg. Nucl. Chem., 1974, 36, 2118.

33 Choudhary Ratan C K, Choudhary K and Mishra L K. J.Indian Chem. Soc., 2003, 83, 693.

34 Patil.S A, Badiger B M, Kudari S M and Kulkarni V H, Trans.Met.Chem.,1983 8,238.

35 Ramachandra B and Narayan B, Indian J. Chem., 1999, 38A.1297.

36 Mishra L K, Jha Y, Sinha B K, Kant R and Sinha, J. Indian Chem. Soc.1999, 176, 65.

37 Prabhakarn C P and Patel C C, J. Inorg. Nucl. Chem, 1972, 34, 3485.

38 Inomata T and Moriwaki T, Bull. Chem. Japan, 1978, 46, 1148.

39 Syamal A and Bari Niazi M M, J. Indian Chem. Soc. Sect. A. 1984, 23, 163

40 Chetan K M, Ashwin S P and Bharat T T, E- J. Chem., 2005, 2(6), 21.

41 Inomata T and Moriwaki, T. Bull. Chem. Japan., 1978, 46, 1148. 
42 Agarwal R C and Rao D S S V, Indian J. Chem., 1982, 21A, 735.

43 Fabretii A C, Grancini G C and Peyronet G, Spectrochim. Acta, 1985, 26A, 698.

44 Rao C N R. Chemical Applications of Infrared Spectroscopy; Academic press. New York, 1963.

45 Mahapatra B B and Saraf S K, J. Indian Chem. Soc., 2003, 80, 696.

46 Vinod Sharma K and Shipra Srivastava, Indian J. Chem., 2006, 45A, 1368-1374.

47 Shikkargol R K, Mallikarjun N N, Siddappa K, Kulkarni V H and Angadi S D, J. Indian Chem. Soc., 2001, 78, 148.

48 Makode J T and Aswar A S, J. Indian Chem. Soc., 2003, 80, 44.

49 Hathaway B J and Billing D E, Co-ord. Chem. Rev, 1970, 6,143.

50 Mishra L K, Jha Y, Sinha B K and Kant R. Rajeswar Singh, J. Indian Chem. Soc., 1999, 16, 65.

51 (a) Hathaway B H and Billing D E, Coord. Chem. Rev. 1970, 6, 143; (b) Sulekha Chandra and Gupta K, Transition Metal Chem., 2002, 27, 19.

52 Simoncini F, Rangone R and Calanni C, Farnance Ed., Prat, 1968, 23(10), 559. Chem. Abstr. 1968, 69, 109851d.

53 Seely H W and Van Demark P J, Microbes in Action, Laboratory of Microbiology, $3^{\text {rd }}$ Ed.. W H Freeman and Co. U.S.A, 1981, 385. 


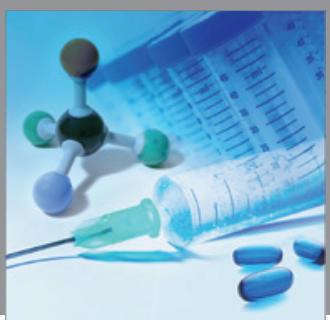

International Journal of

Medicinal Chemistry

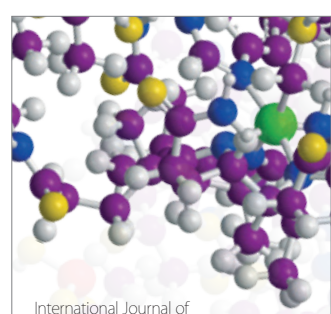

Carbohydrate Chemistry

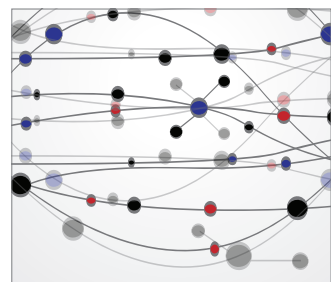

The Scientific World Journal
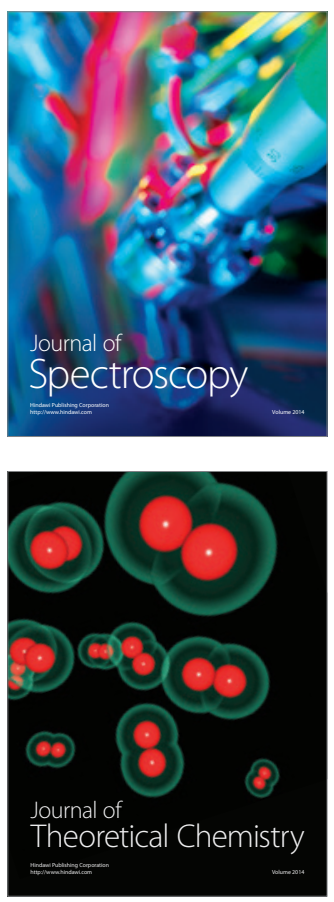
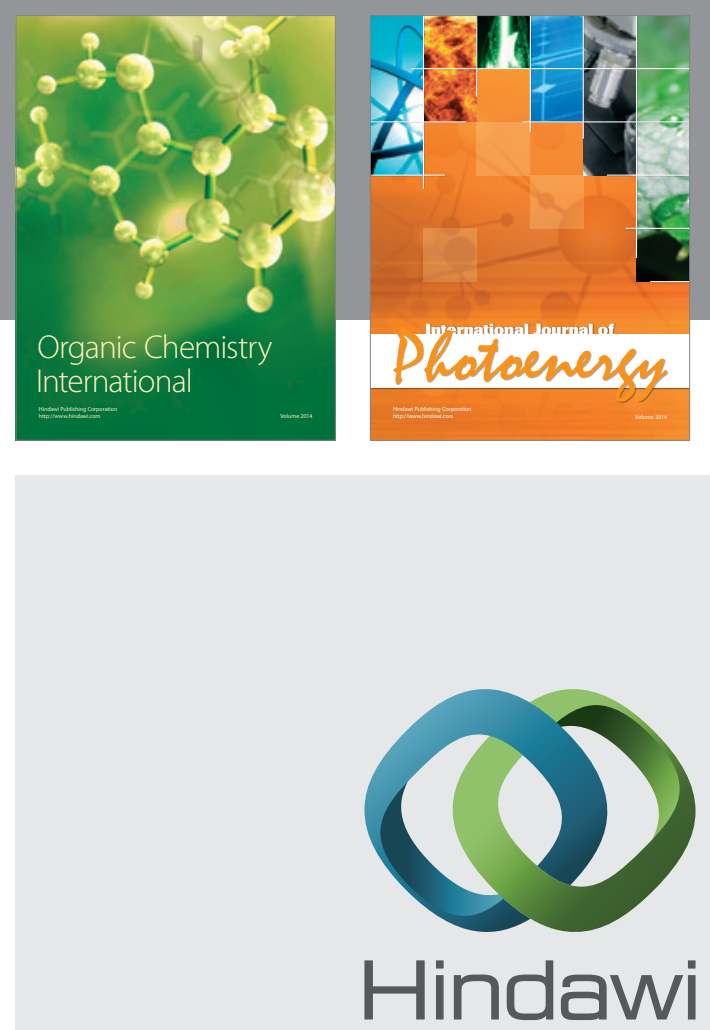

Submit your manuscripts at

http://www.hindawi.com
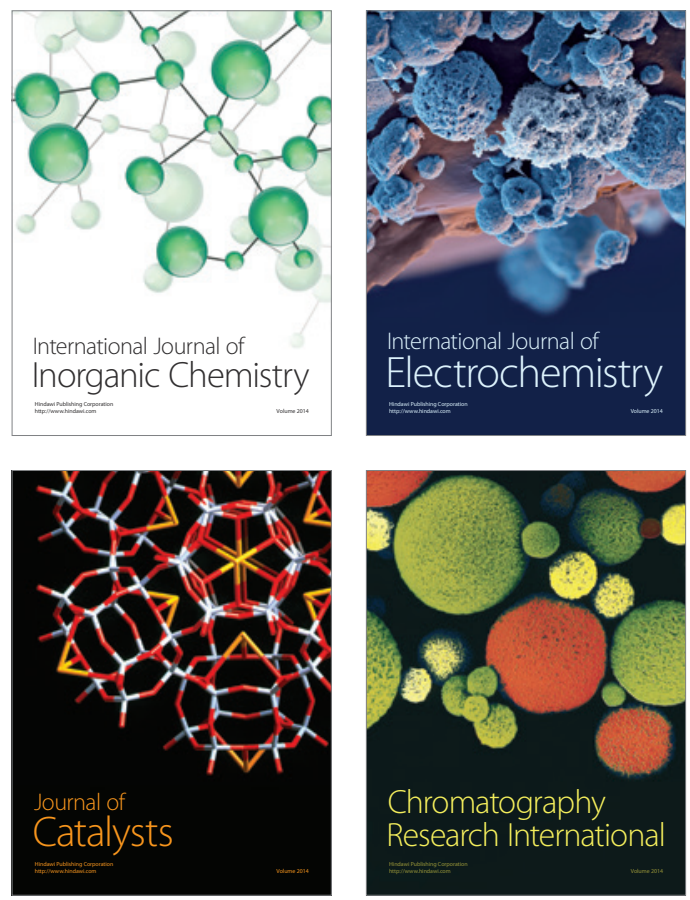
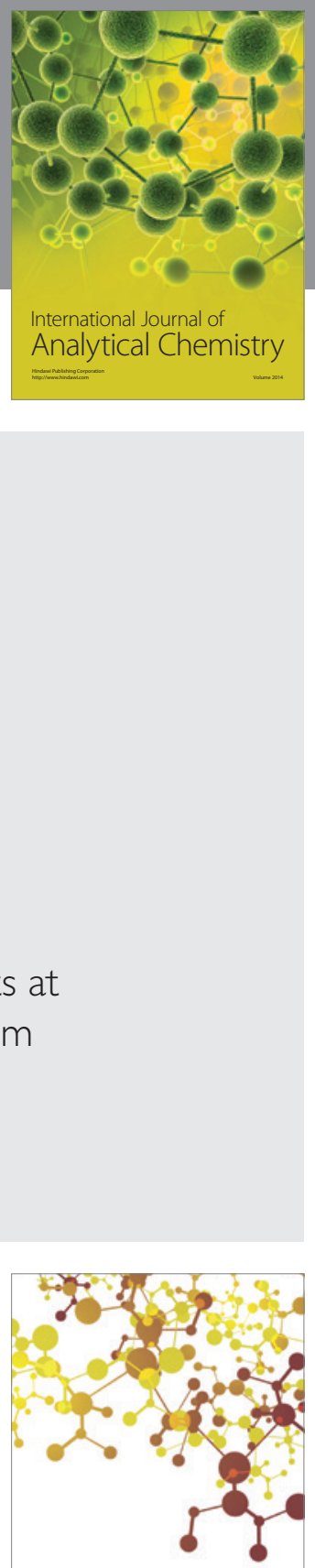

Journal of

Applied Chemistry
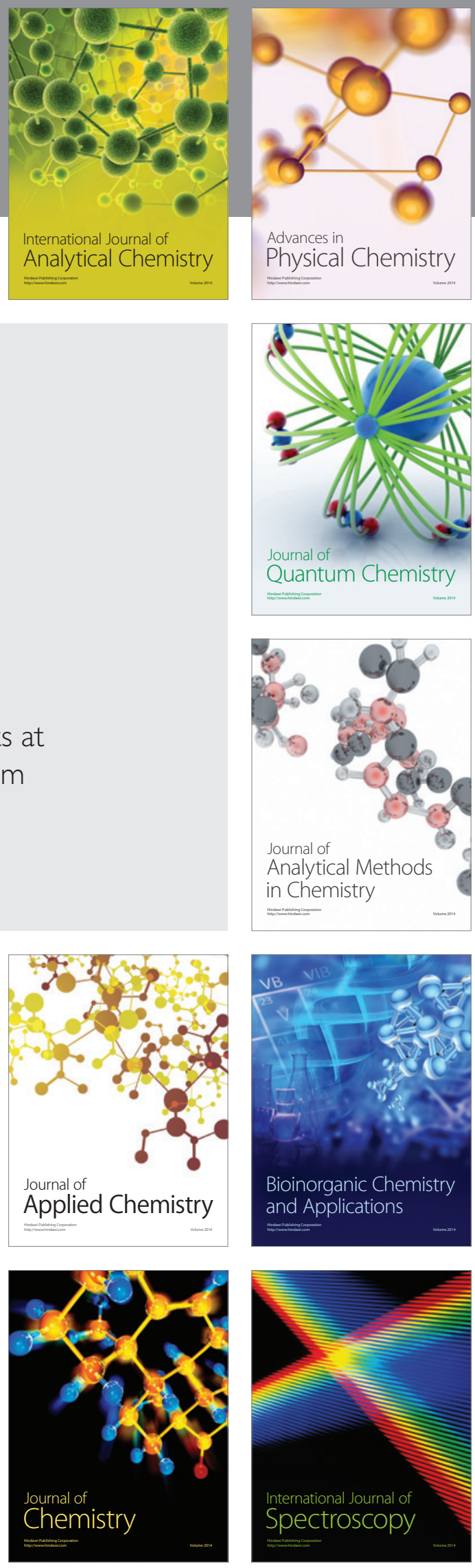